\title{
Development and Performance Evaluation of a Deep Water Synthetic Based Drilling Fluid System
}

\author{
Zengwei Chen1,2, Yongxue Lin ${ }^{1,2}$, Ninghui Dou1,2, Chao Xiao, ${ }^{1,2}$, Hua'an Zhou ${ }^{3}$, Yu Deng3, \\ Yuqiao Zhou ${ }^{4}$, Song Wang4*, Dichen Tan ${ }^{4}$, Huaiyuan Long ${ }^{4}$ \\ ${ }^{1}$ State Key Laboratory of Shale Oil and Gas Enrichment Mechanisms and Effective Development, Beijing, China \\ ${ }^{2}$ Sinopec Research Institute of Petroleum Engineering, Beijing, China \\ ${ }^{3}$ Drilling Fluid Technical Service Company of Chuanqing Drilling Engineering Co.. Ltd., Cheng du, China \\ ${ }^{4}$ Yangtze University, Jingzhou, China \\ Email: sripe@sinopec.com, ${ }^{\star} 1508871707 @ q q . c o m$
}

How to cite this paper: Chen, Z.W., Lin, Y.X., Dou, N.H., Xiao, C., Zhou, H.A., Deng, Y., Zhou, Y.Q., Wang, S., Tan, D.C. and Long, H.Y. (2020) Development and Performance Evaluation of a Deep Water Synthetic Based Drilling Fluid System. Open Journal of Yangtze Gas and Oil, 5, 165-175.

https://doi.org/10.4236/ojogas.2020.54013

Received: June 12, 2020

Accepted: August 4, 2020

Published: August 7, 2020

Copyright $\odot 2020$ by author(s) and Scientific Research Publishing Inc.

This work is licensed under the Creative

Commons Attribution International

License (CC BY 4.0).

http://creativecommons.org/licenses/by/4.0/

\begin{abstract}
With the enhancement of environmental protection awareness, the requirements on drilling fluid are increasingly strict, and the use of ordinary oil-based drilling fluid has been strictly restricted. In order to solve the environmental protection and oil-gas reservoir protection problems of offshore oil drilling, a new synthetic basic drilling fluid system is developed. The basic formula is as follows: a basic fluid ( $80 \%$ Linear a-olefin $+20 \%$ Simulated seawater) $+2.5 \%$ nano organobentonite $+3.5 \%$ emulsifier $\mathrm{RHJ}-5^{\#}+2.5 \%$ fluid loss agent SDJ-1 $+1.5 \% \mathrm{CaO}+$ the right amount of oil wetting barite to adjust the density, and a multifunctional oil and gas formation protective agent YRZ has been developed. The performance was evaluated using a high-low-high-temperature rheometer, a high-temperature and high-pressure demulsification voltage tester, and a high-temperature and high-pressure dynamic fluid loss meter. The results show that the developed synthetic based drilling fluid has good rheological property, demulsification voltage $\geq 500 \mathrm{~V}$, temperature resistance up to $160^{\circ} \mathrm{C}$, high temperature and high pressure filtration loss $<3.5 \mathrm{~mL}$. After adding $2 \%$ - 5\% YRZ into the basic formula of synthetic based drilling fluid, the permeability recovery value exceeds $90 \%$ and the reservoir protection effect is excellent. The new synthetic deepwater drilling fluid is expected to have a good application prospect in offshore deepwater drilling.
\end{abstract}

\section{Keywords}

Deep Water Drilling, Synthetic Based Drilling Fluid, Rheological Property, Emulsion Stability, Filtration, Agent of Reservoir Protection

\section{Introduction}

With the increasing awareness of environmental protection, the requirements 
for the discharge of drilling fluids are becoming stricter, and the use of oil-based drilling fluids has been increasingly restricted. The synthetic based fluid is biodegradable and has no pollution to the environment, so in the exploration and development of oil and gas fields in deep waters, the waste drilling fluid and produced drilling cuttings produced can be directly discharged into the ocean. In addition, it has good lubricating properties and suitable for drilling in well sections with high inclination and horizontal sections [1] [2]. Some synthetic-based drilling fluids do not contain fluorescent substances, which can fundamentally solve the problem of inaccurate interpretation of subsequent logging and well-testing data by oil-based drilling fluids [3] [4]. Since the early 1980s, some oil companies in Western developed countries such as the United States, the United Kingdom, France, and Norway have been committed to research and field application of synthetic-based drilling fluids. In the early 1990s, ester-based drilling fluids were successfully applied in the North Sea of the United Kingdom. The oil field has achieved great success [5] [6] [7]. With continuous in-depth research ester-based ether-based poly- $\alpha$-olefin, acetal and other synthetic-based drilling fluid systems have been developed. Later, under the premise of comprehensive consideration of cost and environmental factors, researchers developed second-generation synthetic-based drilling fluids. The main types of second-generation synthetic-based drilling fluids include linear alpha-olefins, linear alkylbenzenes, linear paraffins, and internal olefins. The second-generation synthetic-based drilling fluids have better kinematic viscosity and environmentally friendly performance than the first-generation, and cost lower. The second-generation synthetic-based drilling fluids have been widely used in deepwater drilling abroad and have achieved huge benefits [8]. However, the rheology of the second-generation synthetic-based drilling fluid is greatly affected by temperature [9]. The viscosity of the drilling fluid is too high at low temperatures, and the viscosity of the drilling fluid is too low at high temperatures, especially the dynamic shear force is too low to carry the solid phase in the drilling fluid effectively [10]. At the same time, synthetic-based drilling fluids have certain thresholds in terms of high-temperature emulsification stability, oil-water ratio, and drilling fluid density [11].

This research presented in this article relies on the oil field chemistry laboratory of Yangtze University and members of the project team. The synthetic-based drilling fluid developed has good rheology, emulsification stability and temperature resistance, which meets the requirements of deep-sea drilling.

\section{Test Instruments and Methods}

\subsection{Experimental Materials}

After various investigations, the experimental materials selected in this paper are of excellent value, wide source and reasonable price. The chemicals used in this article are listed in Table 1. 
Table 1. Chemicals.

\begin{tabular}{lll}
\hline Name & Origin & Note: \\
\hline Nano Organic Bentonite & Zhejiang Fenghong New Material Co., Ltd. & $20 \%$ simulated seawater: \\
Emulsifier RHJ-1 - 5 & Hubei Tianhe Technology Co., Ltd. & $100 \mathrm{ml}$ distilled water + \\
Fluid loss agent SDJ-1 & Hubei Tianhe Technology Co., Ltd. & $\begin{array}{l}\mathrm{MgCl}_{2}+0.22 \mathrm{~g} \mathrm{MgSO}_{4} \\
+0.14 \mathrm{~g} \mathrm{CaSO}_{4}+0.03 \mathrm{~g}\end{array}$ \\
C-14 n-a-olefin & British BP Oil Company & $\mathrm{KCl}$ \\
$\begin{array}{l}\text { Modified oil wetting barite } \\
\text { BaSO }_{4}\end{array}$ & Hubei Songzi Barite Factory & \\
Multifunctional oil and gas $_{\text {layer protective agent YRZ }}$ & Jointly developed by Sinopec Engineering & \\
$20 \%$ simulated seawater & Research Institute and Yangtze University & \\
\hline
\end{tabular}

\subsection{Preparation and Experimental Method of the Synthetic Based Fluid}

1) Preparation of synthetic based drilling fluid. Add the wetting agent, emulsifier and $20 \%$ calcium chloride brine to the synthetic based liquid in turn, and after stirring for $30 \mathrm{~min}$, add nano-organic bentonite and fluid loss additive, continue to stir for 30 - $60 \mathrm{~min}$, add the required changes After wetting the barite with synthetic oil, stir for $30 \mathrm{~min}$.

2) Conventional performance test of synthetic-based drilling fluid. The test methods for the conventional performance of synthetic-based drilling fluids refer to GB/T16782-1997 “Oil-based drilling fluid field test procedures" for testing.

3) Viscosity-temperature characteristic test. Pour the synthetic-based drilling fluid to be tested into a six-speed rotary viscometer, and then place it in a high-low-high temperature drilling fluid rheometer, with a constant temperature of 30 minutes, so that the temperature and rheometer of the drilling fluid in the sample test cup Set the temperature to be consistent, start the test procedure, and start to test the high-low-high temperature rheology of synthetic based drilling fluid.

4) Oil and gas layer damage test. The temporary plugging depth is tested according to the method of the permeability gradient tester; the damage degree of the synthetic based drilling fluid to the oil and gas layer is evaluated by using artificial cores. Conduct the test according to the industry standard SY/T6540-2002 "Drilling fluid completion fluid damages the oil and gas layer "Indoor Evaluation $\mathrm{Me}$ thod". The experimental instruments used in this article are listed in Table 2.

\section{Optimization of Synthetic-Based Drilling Fluid System}

In order to determine the formula of the synthetic based drilling fluid, the required treatment agent was optimized, and the initial formula was determined as follows: base fluid (linear a-olefin $+20 \%$ simulated seawater) + nano-organic bentonite + emulsifier + fluid loss control agent SDJ-1 + 1.5\% lime $\mathrm{CaO}+$ appropriate amount of modified oil to wet barite $\mathrm{BaSO}_{4}$. 
Table 2. Laboratory apparatus.

\begin{tabular}{|c|c|}
\hline Name & Origin \\
\hline Six-speed rotary viscometer & Qingdao Haitongda Instrument Company \\
\hline API and HTHP fluid loss tester & Qingdao Haitongda Instrument Company \\
\hline High-speed stirrer & Qingdao Haitongda Instrument Company \\
\hline Density meter & Qingdao Haitongda Instrument Company \\
\hline $\begin{array}{l}\text { High temperature and high pressure } \\
\text { demulsification voltage tester }\end{array}$ & $\begin{array}{l}\text { Jointly developed by Yangtze University and Hubei } \\
\text { Chuanglian Petroleum Technology Co., Ltd. }\end{array}$ \\
\hline $\begin{array}{l}\text { Drilling fluid high-low-high temperature } \\
\text { drilling fluid rheological test Instrument }\end{array}$ & $\begin{array}{l}\text { Jointly developed by Yangtze University and Hubei } \\
\text { Chuanglian Petroleum Technology Co., Ltd. }\end{array}$ \\
\hline $\begin{array}{l}\text { JHDS-2 high temperature and high pressure } \\
\text { dynamic water loss instrument }\end{array}$ & $\begin{array}{l}\text { Jointly developed by Yangtze University and Hubei } \\
\text { Chuanglian Petroleum Technology Co., Ltd. }\end{array}$ \\
\hline JHST-2 permeability gradient tester & $\begin{array}{l}\text { Jointly developed by Yangtze University and Hubei } \\
\text { Chuanglian Petroleum Technology Co., Ltd. }\end{array}$ \\
\hline
\end{tabular}

\subsection{Based Fluid:Water Ratio}

The effects of the ratio of different base fluids to simulated seawater on the rheology and emulsification stability of synthetic based drilling fluids were studied. The experimental results are shown in Table 3. As the proportion of synthetic based drilling fluid decreases, the apparent viscosity and plastic viscosity of the synthetic based drilling fluid have a certain upward trend, and the emulsification stability shows a downward trend. In order to ensure the demulsification voltage of the synthetic based drilling fluid must be $\geq 400 \mathrm{~V}$ [12], the proportion of water phase should be no more than $30 \%$.

Table 3. Different base fluids of synthetic based drilling fluids: performance of water ratio

\begin{tabular}{rrrrrr}
\hline Base fluid:sea water (V/V) & AV/mPa.S & PV/mPa.S & $\mathrm{YP} / \mathrm{mPa} \cdot \mathrm{S}$ & $\mathrm{Gel} / \mathrm{Pa} / \mathrm{Pa}$ & $\mathrm{ES} / \mathrm{V}$ \\
\hline $90: 10$ & 16.0 & 14 & 2.0 & $3 / 1.0$ & 1048 \\
$85: 15$ & 18.0 & 15 & 3.0 & $4 / 1.5$ & 658 \\
$80: 20$ & 22.0 & 18 & 4.0 & $6 / 2.0$ & 586 \\
$70: 30$ & 28.5 & 24 & 4.5 & $8 / 3.0$ & 504 \\
$60: 40$ & 30.5 & 25.5 & 4.5 & $8 / 3.5$ & 385 \\
\hline
\end{tabular}

\subsection{Preferred Emulsifier}

The emulsifier RHJ-1 $-5^{\#}$ are selected and added to the drilling fluid base formulation respectively. The effects on the rheology of the synthetic based drilling fluid and the emulsion breaking voltage ES are shown in Table 4. It can be seen from Table 4 that the synthetic based drilling fluid configured with $5^{\#}$ emulsifier has the highest demulsification voltage value, indicating the highest stability, and the prepared synthetic based drilling fluid system can meet the rheology and emulsification of drilling fluid in deep water drilling operations Stability requirements can be found from the following references [13] [14] [15] [16]. 
Table 4. Influence of emulsifier on the performance of synthetic based drilling fluid at $50^{\circ} \mathrm{C}$.

\begin{tabular}{rrrrrr}
\hline Emulsifier & AV/mPa.S & PV/mPa.S & YP/Pa & API $_{\mathrm{FL}} / \mathrm{ml}$ & ES/V \\
\hline $3.5 \% 1^{*}$ & 25.5 & 22 & 3.5 & 4.9 & 252 \\
$3.5 \% 2^{*}$ & 27.5 & 24 & 3.5 & 5.2 & 234 \\
$3.5 \% 3^{\#}$ & 33.0 & 29 & 4.0 & 4.7 & 190 \\
$3.5 \% 4^{*}$ & 31.0 & 28 & 3.0 & 3.8 & 354 \\
$3.5 \% 5^{*}$ & 29 & 24.5 & 4.5 & 3.3 & 550 \\
\hline
\end{tabular}

\subsection{Optimization of Fluid Loss Additives}

Several fluid loss additives for drilling fluids were selected and added to the basic formula of synthetic-based drilling fluids. The rheology, normal temperature and high temperature and high pressure water loss were measured respectively. The results are shown in Table 5, which can be seen from Table 5. The API and HTHP fluid loss with the addition of $2.5 \%$ fluid loss agent SDJ- 1 are the smallest.

Table 5. Temperature resistance performance of synthetic based drilling fluid system.

\begin{tabular}{rrrrrrr}
\hline Fluid loss agent & $\mathrm{AV} / \mathrm{mPa} \cdot \mathrm{S}$ & $\mathrm{PV} / \mathrm{mPa} \cdot \mathrm{S}$ & $\mathrm{YP} / \mathrm{Pa}$ & $\mathrm{HTHP}_{\mathrm{FL}} / \mathrm{mL}$ & $\mathrm{API}_{\mathrm{FL}} / \mathrm{ml}$ & $\mathrm{ES} / \mathrm{V}$ \\
\hline $2.5 \% \mathrm{SPNH}$ & 25 & 18 & 7 & 3.8 & 4.2 & 601 \\
$2.5 \% \mathrm{PAC}$ & 28 & 21 & 7 & 4.2 & 3.5 & 622 \\
$2.5 \% \mathrm{CMC}$ & 28 & 20 & 8 & 4.5 & 3.8 & 620 \\
$2.5 \% \mathrm{SK}-2$ & 27 & 19 & 8 & 5.1 & 4.6 & 613 \\
$2.5 \% \mathrm{SDJ}-1$ & 24 & 18 & 6 & 3.2 & 1.6 & 625 \\
\hline
\end{tabular}

\subsection{Addition of Nano Organic Bentonite}

The nano organic bentonite can be quickly dispersed in the synthetic based fluid to form a space grid structure with a certain strength to improve the viscosity, cutting and emulsification stability of the drilling fluid. The influence of the amount of nano-organic bentonite on the rheology and emulsification stability of synthetic-based drilling fluid was evaluated indoors. It can be seen from Table 6 that increasing the amount of nano-organic bentonite increases the demulsification voltage, viscosity and shear force of the synthetic-based drilling fluid. It is recommended to add $2 \%-3 \%$ of nano-organic bentonite to the synthetic-based drilling fluid system.

Table 6. Influence of the addition of nano organobentonite on the performance of synthetic based drilling fluid.

\begin{tabular}{rrrrrr}
\hline Nano Organic Bentonite/\% & $\mathrm{AV} / \mathrm{mPa} \cdot \mathrm{S}$ & $\mathrm{PV} / \mathrm{mPa} \cdot \mathrm{S}$ & $\mathrm{YP} / \mathrm{mPa} \cdot \mathrm{S}$ & $\mathrm{Gel} / \mathrm{Pa} / \mathrm{Pa}$ & $\mathrm{ES} / \mathrm{V}$ \\
\hline 1.5 & 16.0 & 14 & 2.0 & $2 / 0.5$ & 520 \\
2.0 & 21.0 & 17 & 4.0 & $6 / 2.0$ & 601 \\
2.5 & 25.0 & 20 & 5.0 & $7 / 2.8$ & 658 \\
3.0 & 32.0 & 26 & 6.0 & $8 / 3.0$ & 645 \\
3.5 & 36.5 & 29.5 & 7.0 & $9 / 4.5$ & 583 \\
\hline
\end{tabular}




\subsection{The Amount of Modified Oil Wetting Barite}

Using modified oil to wet the barite to increase the weight, the performance of the synthetic-based drilling fluid increased from $1.05 \mathrm{~g} / \mathrm{cm}^{3}$ to $1.80 \mathrm{~g} / \mathrm{cm}^{3}$ and after $160^{\circ} \mathrm{C}$ and $16 \mathrm{~h}$ high temperature aging the results are shown in Table 7. It is not difficult to see that the synthetic-based drilling fluid can accommodate more modified oil-wet barite. As the content of modified oil-wet barite increases, the rheological parameters of the drilling fluid increase uniformly and the emulsion stability is relatively stable.

Table 7. Performance of synthetic based drilling fluids at different densities.

\begin{tabular}{rrrrrr}
\hline$\rho / g / \mathrm{cm}^{3}$ & $\mathrm{AV} / \mathrm{mPa} \cdot \mathrm{S}$ & $\mathrm{PV} / \mathrm{mPa} \cdot \mathrm{S}$ & $\mathrm{YP} / \mathrm{Pa}$ & $\mathrm{Gel} / \mathrm{Pa} / \mathrm{Pa}$ & $\mathrm{ES} / \mathrm{V}$ \\
\hline 1.05 & 16.0 & 13.0 & 3.0 & $4.0 / 1.0$ & 550 \\
1.10 & 17.5 & 14.0 & 3.5 & $5.0 / 1.5$ & 590 \\
1.20 & 19.0 & 15.0 & 4.0 & $6.0 / 2.0$ & 599 \\
1.40 & 22.5 & 17.5 & 5.0 & $6.5 / 2.0$ & 603 \\
1.60 & 24.5 & 19.0 & 5.5 & $7.0 / 2.0$ & 589 \\
1.80 & 27.5 & 21.5 & 6.0 & $7.0 / 3.0$ & 590 \\
\hline
\end{tabular}

Through the above experimental research, the formula of the synthetic based drilling fluid is finally determined as follows: base fluid (80\% linear a-olefin + $20 \%$ simulated seawater) $+2 \%-3 \%$ nano-organic bentonite $+3.5 \%$ emulsifier RHJ-1 - $5^{\#}+2.5 \%$ fluid loss control agent SDJ-1 $+1.5 \%$ lime $\mathrm{CaO}+$ appropriate amount of modified oil wetted barite $\mathrm{BaSO}_{4}$ to adjust density.

\section{Performance Evaluation of Synthetic Based Drilling Fluid}

\subsection{Temperature Resistance of Synthetic Based Drilling Fluid}

The performance of the drilling fluid was evaluated in the laboratory after high-temperature aging at $100^{\circ} \mathrm{C}-180^{\circ} \mathrm{C}$ for $16 \mathrm{~h}$. The results are shown in Table 8. After aging in the temperature range of $100^{\circ} \mathrm{C}-160^{\circ} \mathrm{C}$, the basic performance of synthetic-based drilling fluid has a small change range, showing that the synthetic-based drilling fluid has good temperature resistance.

Table 8. Temperature resistance performance of synthetic based drilling fluid system.

\begin{tabular}{rrrrrr}
\hline $\mathrm{T} /{ }^{\circ} \mathrm{C}$ & $\mathrm{AV} / \mathrm{mPa} \cdot \mathrm{S}$ & $\mathrm{PV} / \mathrm{mPa} \cdot \mathrm{S}$ & $\mathrm{YP} / \mathrm{Pa}$ & $\mathrm{FL}_{\mathrm{HTHP}} / \mathrm{mL}$ & $\mathrm{ES} / \mathrm{V}$ \\
\hline 100 & 22 & 18 & 4 & 2.2 & 601 \\
120 & 23 & 19 & 4 & 2.6 & 622 \\
140 & 25 & 20 & 5 & 2.9 & 620 \\
160 & 27 & 22 & 5 & 3.2 & 613 \\
180 & 36 & 28 & 8 & 5.6 & 420 \\
\hline
\end{tabular}

\subsection{High-Low-High Temperature Rheology of Synthetic Based Drilling Fluid}

The high-low temperature drilling fluid rheometer was used to study the 
high-low-high temperature rheology of synthetic-based drilling fluid. The evaluation results are shown in Table 9. It can be seen from Table 9 that when the temperature changes from high to low to high, the viscosity and shear force of the synthetic based drilling fluid also change accordingly, and its emulsification stability is relatively stable. Therefore, the synthetic-based drilling fluid developed is suitable for deepwater drilling operations.

Table 9. Influence of high-, low- and high temperature of synthetic based drilling fluid on performance.

\begin{tabular}{rccccc}
\hline $\mathrm{T} /{ }^{\circ} \mathrm{C}$ & $\mathrm{AV} / \mathrm{mPa} \cdot \mathrm{S}$ & $\mathrm{PV} / \mathrm{mPa} \cdot \mathrm{S}$ & $\mathrm{YP} / \mathrm{Pa}$ & $\mathrm{Gel} / \mathrm{Pa} / \mathrm{Pa}$ & $\mathrm{ES} / \mathrm{V}$ \\
\hline 100 & 32 & 28 & 4 & $7 / 2$ & 621 \\
50 & 36 & 31 & 5 & $6 / 2$ & 620 \\
20 & 39 & 33 & 6 & $6 / 2$ & 601 \\
10 & 42.5 & 36 & 6.5 & $6 / 2$ & 595 \\
3 & 48.5 & 41.5 & 7.0 & $6 / 3$ & 580 \\
10 & 44 & 37.5 & 6.5 & $6 / 3$ & 590 \\
20 & 41 & 35.5 & 5.5 & $6 / 2$ & 595 \\
50 & 39 & 33.5 & 5.5 & $7 / 2$ & 600 \\
100 & 36.5 & 22 & 4 & $7 / 3$ & 615 \\
\hline
\end{tabular}

\subsection{Protective Effect of Oil and Gas Layers}

In order to better protect the oil and gas layer, an oil and gas layer protective agent YRZ was developed. The specific preparation method is as follows: First, distill the crude C9 aromatics fraction, collect the fractions at different temperatures, weigh a certain amount of initiator (including a certain ratio of peroxide and metal salt), add 100 grams of refined C9 aromatics, and heat up at about $160^{\circ} \mathrm{C}$, the reaction was carried out for 10 hours with stirring. The reaction mixture was distilled under reduced pressure to remove the solvent. The resulting product was petroleum resin.

Then select acrylamide (AM), N,N-methylene bisacrylamide (MBA), acrylic acid (AA) and cationic monomer dimethylallyl ammonium chloride (DMDAAC), etc. as synthetic polymer monomers, white oil is the dispersion medium, Span80/Tween 80 is the compound emulsifier, n-butanol is the co-emulsifier. Under the initiation of redox system ammonium persulfate-sodium bisulfite, reverse phase microemulsion polymerization method is used to synthesize good blocking performance.

Finally put petroleum resin and anti-collapse plugging material into a kneader according to a certain proportion, and add a small amount of surfactant, after kneading evenly, and then drying, crushing, after a 200-mesh sieve, thereby obtaining multifunctional oil and gas layer protective agent YRZ with different particle sizes. The evaluation of the reservoir protection effect is mainly based on the drilling fluid backflow permeability recovery value, temporary plugging strength, temporary plugging depth and other aspects. The synthetic-based 
drilling fluid system for protecting oil and gas layers is: the basic formula of synthetic-based drilling fluid $+1 \%$ to $5 \%$ multifunctional oil and gas layer protective agent YRZ.

After adding the multi-functional oil and gas layer protection agent YRZ, the drilling fluid forms a layer of dense mud cake on the end face of the core, which is the shielding temporary plugging layer. The laboratory research evaluates the compressive strength of the shielding temporary plugging ring by changing the displacement pressure. For cores with different permeability, the shield temporary plugging ring formed on the core end face is reversely displaced under a displacement pressure difference of 3.0 $\mathrm{MPa}$, and then the displacement pressure difference is increased to $10.0 \mathrm{MPa}$, and the corresponding core permeability is measured.

As shown in Table 10, as the displacement pressure increases from $3.5 \mathrm{MPa}$ to $10 \mathrm{MPa}$, the core permeability is all $<0.01 \times 10^{-3} \mu \mathrm{m}^{2}$, indicating that a shield layer with sufficient strength has been formed inside the core, preventing the liquid phase and solid phase from further Enter the core and play a temporary blocking role.

Table 10. Shielding temporary blocking strength evaluation experiment.

\begin{tabular}{rrrrrr}
\hline Core & $\mathrm{K}_{0}$ & $\mathrm{~K}_{3.5}$ & $\mathrm{~K}_{6.0}$ & $\mathrm{~K}_{8.0}$ & $\mathrm{~K}_{10}$ \\
\cline { 3 - 6 } & & & $\left(10^{-3} \boldsymbol{\mu m}^{2}\right)$ & & \\
\hline 138 & 115.23 & $<0.01$ & $<0.01$ & $<0.01$ & $<0.01$ \\
29 & 216.89 & $<0.01$ & $<0.01$ & $<0.01$ & $<0.01$ \\
63 & 98.39 & $<0.01$ & $<0.01$ & $<0.01$ & $<0.01$ \\
235 & 22.56 & $<0.01$ & $<0.01$ & $<0.01$ & $<0.01$ \\
312 & 58.20 & $<0.01$ & $<0.01$ & $<0.01$ & $<0.01$ \\
\hline
\end{tabular}

Note: $\mathrm{K}_{0}$ is the original permeability of the core; $\mathrm{K}_{3.5}, \mathrm{~K}_{6.0}, \mathrm{~K}_{8.0}$ and $\mathrm{K}_{10.0}$ are the permeability measured with kerosene after the temporary plugging and the pressure difference is 3.5, 6.0, 8.0 and 10.0 MPa respectively.

Temporary plugging depth is a main technical index for evaluating the protection effect of shielded temporary plugging oil and gas layers. The requirement of shielded temporary plugging technology is that the plugging is shallow, pluggable, and is a temporary blockage. Select a few artificial cores in Table 11, use JHST-2 permeability gradient tester to do temporary plugging experiment first, then intercept a certain length of core along the temporary plugging end, then measure the permeability of the remaining core section and compare the core of the remaining core section. The permeability is the same as the original permeability of the entire core. If the two are close, the core length of the intercepted part can be regarded as the temporary plugging depth of the temporary plugging layer to a certain extent. The plugging depth is about $1 \mathrm{~cm}$, which indicates that after the oil and gas layer protection agent YRZ is added to the synthetic-based drilling fluid system, the temporary blocking effect of the shield is good, and the dense shield layer is quickly formed only in the shallow layer of the core.

The change of core permeability after adding $2 \%-5 \%$ YRZ to the synthetic 
based drilling fluid was evaluated by JHDS-2 high temperature and high pressure water loss meter. The experimental results are shown in Table 12. The drilling fluid with multifunctional oil and gas layer protection agent YRZ was added. After the dynamic damage test, the shielding ring quickly formed at the contact end of the core and the drilling fluid prevented the liquid and solid phases from further intruding into the pore throat. The average permeability recovery value of the core measured after kerosene flowback reached more than $90 \%$. Considering the cost and other factors, it is recommended to add $3 \%$ multi-functional oil and gas layer protection agent YRZ to the basic formulation of synthetic-based drilling fluid, which can meet the requirements of on-site oil and gas layer protection.

Table 11. Temporary plugging depth evaluation of synthetic based drilling fluids.

\begin{tabular}{|c|c|c|c|c|c|}
\hline Core number & $\begin{array}{r}\text { Core length } \\
\text { Lo }(\mathrm{cm})\end{array}$ & $\mathrm{K}_{0}\left(10^{-3} \mu \mathrm{m}^{2}\right)$ & $\begin{array}{r}\text { Intercept } \\
\text { length } \mathrm{Li}(\mathrm{cm})\end{array}$ & $\mathrm{Ki}\left(10^{-3} \mu \mathrm{m}^{2}\right)$ & $\begin{array}{r}\text { Temporary blocking } \\
\text { depth }(\mathrm{cm})\end{array}$ \\
\hline 120 & 5.89 & 38.95 & 1.02 & 38.20 & $\leq 1.02$ \\
\hline 45 & 6.18 & 185.40 & 0.95 & 179.65 & $\leq 0.95$ \\
\hline 98 & 5.98 & 77.35 & 1.21 & 79.58 & $\leq 1.21$ \\
\hline 76 & 6.01 & 68.23 & 1.05 & 67.29 & $\leq 1.05$ \\
\hline 28 & 6.07 & 54.20 & 0.96 & 55.30 & $\leq 0.96$ \\
\hline 257 & 5.86 & 321.78 & 1.02 & 315.28 & $\leq 1.02$ \\
\hline 372 & 5.96 & 12.54 & 1.08 & 11.95 & $\leq 1.08$ \\
\hline
\end{tabular}

Note: The experimental conditions for temporary plugging of synthetic based drilling fluid are $3.5 \mathrm{MPa}$ differential pressure, $10 \mathrm{MPa}$ confining pressure and $30 \mathrm{~min}$.

Table 12. Reservoir protection effect of synthetic based drilling fluid.

\begin{tabular}{|c|c|c|c|c|c|c|c|}
\hline \multirow[t]{2}{*}{ Core } & \multirow{2}{*}{$\begin{array}{r}\mathrm{K}_{0} \\
\left({ }^{*} 10^{-3}\right.\end{array}$} & \multirow{2}{*}{$\begin{array}{r}\mathrm{K}_{\mathrm{d}} \\
\left.\mu \mathrm{m}^{2}\right)\end{array}$} & \multirow[t]{2}{*}{$\begin{array}{r}\mathrm{K}_{\mathrm{d}} \\
/ \mathrm{K}_{0}\end{array}$} & \multicolumn{3}{|c|}{$\begin{array}{r}\text { Temporary blocking test } \\
\text { conditions }\end{array}$} & \multirow[b]{2}{*}{ Drilling fluid system } \\
\hline & & & & \multicolumn{2}{|c|}{$\begin{array}{l}\text { Differential Time } \\
\text { pressure (min) } \\
(\mathrm{MPa})\end{array}$} & \multirow{2}{*}{$\begin{array}{r}\begin{array}{r}\text { Filtrate } \\
\text { volume } \\
(\mathrm{mL})\end{array} \\
1.25\end{array}$} & \\
\hline 56 & 36.81 & 30.27 & 82.24 & 10.0 & 60 & & $\begin{array}{c}\text { Basic formula of synthetic based } \\
\text { drilling fluid }\end{array}$ \\
\hline 189 & 43.52 & 39.98 & 91.86 & 10.0 & 60 & 1.0 & $\begin{array}{c}\text { Basic formula of synthetic based } \\
\text { drilling fluid }+2 \% \text { YRZ }\end{array}$ \\
\hline 26 & 136.70 & 127.29 & 93.12 & 10.0 & 60 & 0.0 & $\begin{array}{c}\text { Basic formula of synthetic based } \\
\text { drilling fluid }+3 \% \text { YRZ }\end{array}$ \\
\hline 247 & 29.65 & 28.29 & 95.43 & 10.0 & 60 & 0.0 & $\begin{array}{c}\text { Basic formula of synthetic based } \\
\text { drilling fluid }+5 \% \text { YRZ }\end{array}$ \\
\hline
\end{tabular}

\section{Conclusions}

1) The basic formula of the synthetic-based drilling fluid developed as the following: base fluid $(80 \%$ linear a-olefin $+20 \%$ simulated seawater $)+2 \%-3 \%$ nano-organic bentonite $+3.5 \%$ emulsifier RHJ-1 $-5 \#+2.5 \%$ filtration Loss agent 
$\mathrm{SDJ}-1+1.5 \%$ lime $\mathrm{CaO}+$ appropriate amount of modified oil wetted barite $\mathrm{Ba}$ $\mathrm{SO}_{4}$ to adjust density.

2) The synthetic-based drilling fluid developed has good rheology; good emulsification stability, demulsification voltage above $500 \mathrm{~V}$; good temperature resistance, temperature resistance up to $160^{\circ} \mathrm{C}$.

3) A multi-functional oil and gas layer protection agent YRZ has been developed. After adding 2\% - 5\% YRZ to the basic formula of synthetic-based drilling fluid, its permeability recovery value exceeds $90 \%$, the oil and gas layer protection effect is excellent, and it has certain application prospects.

\section{Fund Project}

National Science and Technology Major Project.

\section{Conflicts of Interest}

The authors declare no conflicts of interest regarding the publication of this paper.

\section{References}

[1] Zhang, Y. and Ren, L.R. (2001) Experimental Study of Linear Paraffin-Based Drilling Fluid. Modern Geology, 15, 103-107.

[2] Xu, M.B., Zhang, N., Wang, C.J., et al. (2004) Performance of Deep Water Drilling Fluid System Based on Polylebene-Olefin Synthesis. Journal of Jianghan Petroleum Institute, 26, 112-113.

[3] Peng, S.P. (2004) Research on Synthetic Base Drilling Fluids. Southwest Petroleum Institute, Chengdu.

[4] Ke, D. (2017) Research on Environmental Protection Based Drilling Fluid System for Gas Oil Synthesis. China University of Petroleum, Beijing.

[5] Luo, J.S., Mo, C.X., Liu, Z.M., et al. (2009) Research and Application of Synthetic Drilling Fluids Based on Gas Oil Production. Drilling Fluids and Completion Fluids, 26, 7-11.

[6] Jiang, Z., Shu, F.C., Xiang, X.J., et al. (2009) Indoor Study of All-Oil Synthetic Base Drilling Fluid. Drilling Fluid and Completion Fluid, 26, 19-20.

[7] Hu, S.Q., Lei, X., Yu, J.M., et al. (2010) Indoor Study of Deep Water and Low Temperature Synthetic Base Drilling Fluid. Journal of Jianghan Petroleum Institute, 32, 120-123.

[8] Burrows, K., Evans, J., Hall, J., et al. (2001) New Low Viscosity Ester Is Suitable for Drilling Fluids in Deepwater Applications. SPE/EPA/DOE Exploration and Production Environmental Conference, San Antonio, 26-28 February, SPE-66553-MS. https://doi.org/10.2118/66553-MS

[9] Watson, P., Kolstad, E., Borstmayer, R., et al. (2003) An Innovative Approach to Development Drilling in Deepwater Gulf of Mexic. SPE/ IADC Drilling Conference, Amsterdam, 19-21 February, SPE-79809-MS. https://doi.org/10.2118/79809-MS

[10] Kirsner, J., Don Siems, H., et al. (2005) Method of Formulating Using a Drilling Mud with Fragile Gels. US6887832.

[11] Yue, Q.S., Liu, S.J., Geng, Y.N., et al. (2011) Performance of Deepwater Linear Lebene-Olefin Synthetic Drilling Fluids. Drilling Fluids and Completion Fluids, 28, 
27-29.

[12] Sui, S.Q., Tang, X., Hou, Y.G., et al. (2011) A New Type of Linear Lebene-Olefin Synthetic Drilling Fluid. Drilling Fluid and Completion Fluid, 28, 30-32.

[13] Hu, Y.L., Yue, Q.S. and Liu, S.J. (2012) Research on Deepwater Synthetic Drilling Fluid. Drilling and Production Technology, 35, 71-74.

[14] Wang, J.G., Zhang, X.P., Cao, H., et al. (2013) Application of an Environmentally Friendly Synthetic Drilling Fluid in Horizontal Shale Gas Wells. Natural Gas Industry, 33, 82-85.

[15] Wang, M.G., Xu, X.G., Sun, J.S., et al. (2016) Development and Application of Key Treating Agent for Drilling Fluid Based on Gas Oil Synthesis. Drilling Fluid and Completion Fluid, 33, 30-34.

[16] Yuan, J.X. (2016) Study on Base Oil and System Performance of Nh-So1 Synthetic Drilling Fluid. Drilling and Production Technology, 39, 98-101. 